\title{
Healthcare Workers Are Losing Their Lives in the Battle of Covid-19 All Over the Globe
}

\author{
Tüm Dünyada Sağlık Çalıșanları Covid-19 Nedeniyle \\ Hayatını Kaybediyor
}

Frontline healthcare workers (HCWs) play the most essential role, especially since the Covid-19 breakout, providing care for patients all over the world. In the context of Covid-19, thousands of healthcare workers were infected and hundreds of them have died.

Since there is no systematic reporting system of infected healthcare workers, it is difficult to track down current and accurate data. However, 22.073 cases of Covid-19 among HCWs from 52 countries had been reported to World Health Organization (WHO), until the date of April $11,2020 .{ }^{1}$ These numbers, therefore are not able to fully represent the true number of infected HCWs with Covid-19, globally.

The publications and reports regarding the number of HCW infections are limited. For instance, The National Health Commission of the People's Republic of China has reported that as of February 24, 2020, a total of 3387 patients with Covid-19 in China were health care workers that constitutes $4.4 \%$ of all infected individiuals, and as of April 3, 2020, 23 of them have died because of Covid- 19, which represents $0.69 \%$ of all mortalities. ${ }^{2,3}$ In compliance with a report from Italy, 15.314 infections among HCW were reported on 10th of April 2020, which is $11 \%$ of all infected individuals in Italy. ${ }^{4}$ Another report from Italy suggests that up until April 27, 2020, the total number of deaths of HCWs is 153 , which is $0.57 \%$ of total deaths. ${ }^{5}$ The Centers for Disease Control and Prevention (CDC) released the infection count of United States of America (USA) on 14th of April 2020 and indicated 27 health worker deaths and more than 9200 positive tests have been recorded, based on a small number of test-result reports. In Turkey, a situation report was published which reveals that as of April 1, 2020 the number of HCWs infected is 3474 until the date of April 22, 2020, 38\% of it being medical doctors and 24 HCWs have died from Covid-19 infection, and 14 of them were doctors. ${ }^{6}$

Among HCWs, infections are usually reported as mild cases, whereas severe symptoms and death are also affirmed. ${ }^{7-8}$ While national reports help to understand the severity of the infection among HCW, yet global data is lacking. Therefore we aimed to gather nationwide information regarding HCW infections.

After a collective search through international resources, we gathered a count of 708 deaths among HCWs until April 27, 2020, which represents $0.35 \%$ of total global deaths. ${ }^{25,6,9,10}$ According to WHO's $98^{\text {th }}$ situation report on $27^{\text {th }}$ April 2020, global count of confirmed cases was 2878196 and number of total deaths was 198668 with a mortality rate of $6.9 \% .{ }^{10}$ Among those 708 deaths, 365 (51.5\%) of them were doctors and 126 (17.79\%) were nurses (Table 1). ${ }^{9}$ The mean age of the HCWs was 58. Total of 52 countries were recorded. Highest number of deaths was recorded in Italy (153), which is followed by United States of America (USA) (135), Iran (84), England (70) and Turkey (26) (Table 1). The occupations with the highest number of deaths following doctors were nurses, technicians and hospital staff, and medical directors (Table 1). Most of the doctors died from Covid-19 were general practitioners (21\%), followed by internal medicine specialists $(2.6 \%)$, general surgeons $(2.5 \%)$, pediatricions $(2.4 \%)$ and emergency medicine specialists $(2.2 \%)$, respectively (Table 1$)$.

Factors related with HCW infection may be as follows; working in a higher-risk department, longer duty hours, inadequate adjustments to protective recommendations or improper use of personal protective equipment (PPE). Among these 365 deaths only 8 of the doctors were anesthesiologists, 7 of them were pulmonologists and 4 of them were infectious diseases
Damla Beyazadam', Orhan Alimoglu²

Department of General Surgery, Istanbul Medeniyet University, Faculty of Medicine, Goztepe Training and Research Hospital, Istanbul, Turkey

Department of General Surgery, Istanbul Medeniyet University, Faculty of Medicine, Goztepe Training and Research Hospital, Istanbul, Turkey

Received/Gelis : 10.05 .2020 Accepted/Kabul : 12.05.2020

DOI: 10.21673/anadoluklin.735140

Corresponding author/Yazışma yazarı Orhan Alimoglu

Istanbul Medeniyet University, Faculty of Medicine Goztepe Training and Research Hospital Dr Erkin st. 34722 Kadıkoy, Istanbul, Turkey

E-mail: orhanalimoglu@gmail.com

\section{ORCID}

Damla Beyazadam: 0000-0001-8678-2004 Orhan Alimoglu: 0000-0003-2130-2529 


\begin{tabular}{|c|c|c|c|c|c|}
\hline Occupation & Number & Country & Number & Specialty (Doctors) & Number \\
\hline Medical Doctors & $365(51.5 \%)$ & Italy & $153(21.6 \%)$ & General Practitioner & $149(21 \%)$ \\
\hline Nurse & $126(17.9 \%)$ & USA & $135(19 \%)$ & Internal Medicine & $19(2,6 \%)$ \\
\hline Technician & $26(3.6 \%)$ & Iran & $84(11.8 \%)$ & General Surgeon & $18(2,5 \%)$ \\
\hline Hospital Staff & $21(2.9 \%)$ & England & $70(9.8 \%)$ & Pediatrics & $17(2,4 \%)$ \\
\hline Medical Director & $16(2.2 \%)$ & Turkey & $26(3.6 \%)$ & Emergency Medicine & $16(2,2 \%)$ \\
\hline Dentist & $13(1.8 \%)$ & Brazil & $25(3.5 \%)$ & Cardiology & $13(1,8 \%)$ \\
\hline Pharmacist & $7(0.9 \%)$ & Philippines & $25(3.5 \%)$ & Obstetrics- Gynecology & $11(1,5 \%)$ \\
\hline Others & $109(15.4 \%)$ & China & $24(3.4 \%)$ & Family Medicine & $10(1,4 \%)$ \\
\hline \multirow[t]{13}{*}{ Total } & 708 & Indonesia & $23(3.2 \%)$ & Otorhinolaryngology & $9(1,2 \%)$ \\
\hline & & Mexico & $22(3.1 \%)$ & Pathology & $9(1,2 \%)$ \\
\hline & & Spain & $22(3.1 \%)$ & Psychiatry & $9(1,2 \%)$ \\
\hline & & Ecuador & $17(2, .4 \%)$ & Radiology & $9(1,2 \%)$ \\
\hline & & Others & $82(11.58)$ & Anesthesiology & $8(1,1 \%)$ \\
\hline & & Total & 708 & Urology & $8(1,1 \%)$ \\
\hline & & & & Opthalmology & $7(0,9 \%)$ \\
\hline & & & & Pulmonology & $7(0,9 \%)$ \\
\hline & & & & Neurology & $6(0,8 \%)$ \\
\hline & & & & Infectious Diseases & $4(0,5 \%)$ \\
\hline & & & & Orthopedics & $4(0,5 \%)$ \\
\hline & & & & Others & $32(\% 4,5)$ \\
\hline & & & & Total & 708 \\
\hline
\end{tabular}

specialists, which brings up the question that whether the doctors in these specialties could be more self-adequate and cautious, so that they are better protected than the others. Further collection of data and investigations regarding inadequate PPE, or ineffective measures should be performed in order to make interpretations on that matter. WHO developed risk assessment tools in order to substantially reduce and avoid the risk of infection in HCWs. ${ }^{1}$ It is crucial for us to protect ourselves and others, to understand the infection, take all protective measures, assess the risk and properly evaluate the physical and mental health of the HCWs. With respect to their heroic efforts, we aimed to gather and report these 708 fighters who have given their lives saving others throughout the globe.

\section{REFERENCES}

1. https://www.who.int/docs/default-source/coronaviruse/situation-reports/20200411-sitrep-82-covid-19. pdf?sfvrsn=74a5d15_2 /24.04.2020

2. National Health Commission of the People's Republic of China. Transcript of the press conference of the China-WHO Joint Expert Investigation Team on Covid-19 on February 25, 2020. (In Chinese) (http://www.nhc.gov.cn/xcs/fkdt/2020 02/1575db9286f943f4aa00d9e24e9ed0ba.shtml) / 28.04.2020

3. National Health Commission of the People's Republic of China. Decision of awarding outstanding groups and individuals in the National Health System for excellent work in the prevention and control of Covid-19. March 5, 2020. (In Chinese) (http://www.nhc.gov.cn/xcs/zhengcwj/202003/28c c60d7e33b4dc7bd77af485fabla58.shtml. opens in new tab). /27.04.2020

4. Integrated surveillance of COVID-19 in Italy: 10 April 2020. https://www.epicentro.iss.it/en/coronavirus/bollettino/ Infografica_10aprile\%20ENG.pdf

5. https://portale.fnomceo.it/struttura-e-organizzazione/ /28.04.2020

6. Türkiye’de COVID-19 Tanısı Almış Sağlık Çalışanlarının Sayıs1 Artıyor. https://www.ttb.org.tr/kollar/userfiles/files/ ttbcovid-saglik-calisanlari_-EN-SON.pdf /27.04.2020

7. Liu J, Ouyang L, Guo P, et al. Epidemiological, Clinical Characteristics and Outcome of Medical Staff Infected with COVID-19 in Wuhan, China: A Retrospective Case Series Analysis. medRxiv. 2020:2020.03.09.20033118. doi: 10.1101/2020.03.09.20033118.

8. McMichael TM, Currie DW, Clark S, et al. Epidemiology of Covid-19 in a Long-Term Care Facility in King County, Washington. New England Journal of Medicine. 2020doi: 10.1056/NEJMoa2005412.

9. In Memoriam: Healthcare Workers Who Have Died of COVID-19 https://www.medscape.com/viewarticle/927976\#vp_1 /28.04.2020

10. https://www.who.int/docs/default-source/coronaviruse/situation-reports/20200427-sitrep-98-covid-19. pdf?sfvrsn=90323472_4 /29.04.2020 